Review Article

\title{
Piebaldism in To Balo, South Sulawesi: Brief Report and Literature Review
}

\author{
Cut Muthiadin*, Isna Rasdianah Aziz, Andi Nabila Nurfitrah, Pujarena Putri Idris \\ Department of Biology, Faculty of Science and Technology, Universitas Islam Negeri Alauddin Makassar, \\ South Sulawesi, Indonesia
}

*Corresponding author: cutmuthiadin@uin-alauddin.ac.id.

\begin{abstract}
Piebaldism is an autosomal dominant congenital disorder in pigment as a result of mutations in the KIT gene, mapped on the long arm of chromosome 4. To Balo lived as a carrier of piebaldism genes. There are only four individuals of To Balo communities remained on Pujananting district, South Sulawesi. This study was a brief report and literature review about suspects of Piebaldism in To Balo. Data was collected by observation of depigmentation, interview, and then depicted in pedigree. Phenotypic observations resulted in piebaldism on three individuals of To Balo, showed the same pattern and location of white patches. It is concluded that normal individuals can appear in third-generation when a woman or man carrier of piebaldism married with a normal individual.
\end{abstract}

Keywords: autosomal dominant; genetic disorder; pedigree; piebaldism; To Balo

\section{Introduction}

Piebaldism is an autosomal dominant genetic disorder that is associated with defects in migration and differentiation of melanoblasts from nerve peaks. Its signs similar within vitiligo, noncontagious disorder wherein advanced, patchy loss of pigmentation of skin and repeatedly covering hair, and mucous membranes, results from loss of melanocytes from the involved areas (Spritz, 2007; Koley et al., 2009; Janjua et al., 2007; Neves et al., 2010). However, differed by vitiligo in which is not genetically inherited and it is commonly present at birth and transform little afterward, piebaldism is a genetic congenital pigment abnormality caused by a mutation in proto-oncogene encoding the transmembrane receptor tyrosine kinase KIT (Oiso et al., 2013; Syrris et al., 2002; Richard et al., 2001). It is characterized by leukoderma and poliosis by atypical migration of neural crest-derived melanoblasts in the embryo (Murakami et al., 2004; Yang et al., 2013).

Oiso et al. (2013), stated that piebaldism illustrated by congenital white skin, commonly known as leukoderma and white hair (poliosis) on the frontal scalp, forehead, ventral trunk, and extremities. Winship et al. (1991) have studied a South African family in which nine members extend four generations had piebaldism, and it is shown in the pedigree was indicates autosomal dominant inheritance. To Balo lives in a distant place in the Bulu Pao Mountains, which stretch across the Barru and Pangkep town, Pujananting District, South Sulawesi. Since occupying the area, they have formed a community that is isolated from other communities with the characteristics of each individual that is unusual skin where the whole body, especially the legs, body, and hands, full of white spots. While right in the middle of their foreheads, the patches were also displayed almost in a triangle shape. Therefore they are called the To Balo (local language: Bugis), are refers to people with a patch. Sabran et al. (2018), have been 
studied in To Balo communities, stated that To Balo is an autosomal dominant, similarly with Piebaldism inheritance. However, they have not been able to prove the existence of a KIT gene mutation in people To Balo.

In this study, we observe the pattern of piebaldism inheritance in To Balo in three generations of pedigree analysis. Besides that, we collect the other phenotype data, i.e., the pattern of the patch, pattern of fingerprint, and type of blood. It can be used as the prior in collection data of the probands with molecular genetics in future studies.

\section{Material and Method}

This research is a brief report and literature review, by interviews and phenotypic observations of the patch patterns of people To Balo or Piebaldism. The suspects were the whole population of To Balo, consisting of two households, a total amount of four individuals. Literature review used as a control to give differentiation with other melamine disorders. The data is shown in the pedigree analysis and data of clinical features in To Balo communities.

\section{Results and Discussion}

\subsection{Results}

Based on a survey to three of suspected piebaldism were agree to follow observation of some of the body parts (except in stomach and chest area), below picture as representative of the phenotype of To Balo.
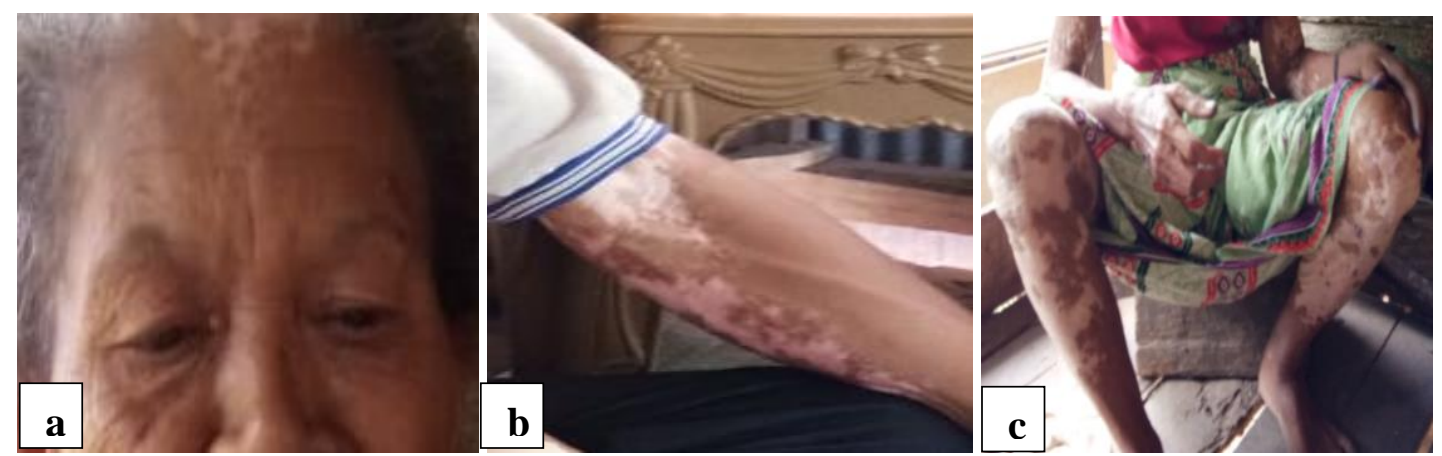

Figure 1. a) Head area; b) Extremities upper area; c) Extremities lower area

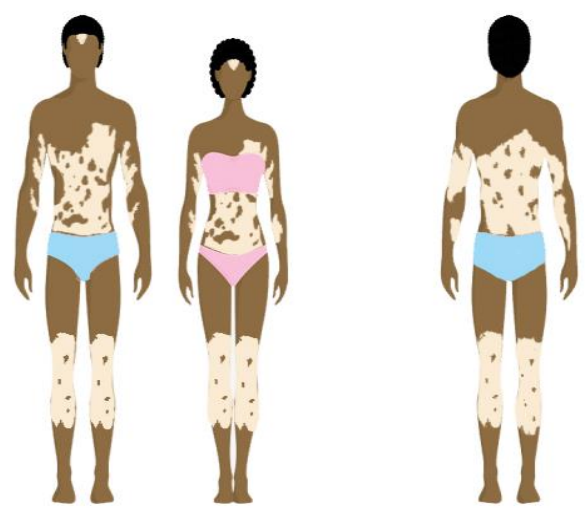

Figure 2. Distribution of depigmentation in To Balo (left: front, right: back) 


\subsection{Discussion}

To Balo community has its uniqueness that exists in Bulo-Bulo Village, Pujananting District, Barru District. Different from this community, it turns out that it has its population limit for those who live in the village. Limitation of the number of people who do not come from the town of Bulo-Bulo or local village officials, but is assumed to be a natural law for the To Balo Community, because the population of the To Balo Community must not exceed the standard set of 11 people. If it reaches the maximum number, then one of the individuals will die and later be born again the same offspring from the community. The highest number of numbers in this unit number, which is nine, becomes the highest and maximum size in the To Balo Community, but as the years go by, the condition decreases, this is caused by the number of individuals who leave their hometowns to migrate and to study in the city, so that the current total population is only 5 (five) individuals remained, based on the results of a survey and information from the head of the village of Bulo-Bulo.

Rochmawati (2016), also Labuda et al. (2010), review that a population is a group of individuals of one species that occupy a place, do a breeding population, and in the process of marriage can be isolated from other types of groups. Thus, the genome of each population is called the genotype. Genotypes owned by members of the population will form a gene pool, where the gene pool will spread in the population and determine its biological form.

\section{Characteristic of depigmentation in To Balo}

Based on the observation of white patch on To Balo individuals, all three individuals have the same white spots from the pattern. There are patches on the head (parietal) it's called white forelock (Figure 1a), on the right hand of the upper arm (humerus), picker (fingers), and cubits (ulna) (Figure 1b), on the chest to the stomach (gaster) and finally on the thigh (femur), knee (patella), shin (tibia) and calf (fibula)(Figure 1c). Unfortunately, the respondents disagree with taking the documentation in the stomach and chest area. Thus we developed a sketch about the distribution of patch in suspect of piebaldism (Figure 2).

The pattern of patches in To Balo almost similarly in all cases, it is symmetrical depigmentation, with a white forelock, but the pattern in the trunk, dorsal, and ventral in To Balo. It is rarely different from cases of piebaldism in someplace, were Xhosa tribal group in the Transkei, $300 \mathrm{~km}$ east of Cape Town (Arianayagam \& Ryan, 2016). The distribution was alike in all, with symmetrical depigmentation involving the medial portion of the forehead, the chin, the ventral aspect of the chest, abdomen, and all extremities (Funkhouser et al., 2019; Park et al., 2002; Hazan, 2005). Besides, sparing most of the hands and the feet but did not present in the dorsal trunk. All subjects had a white forelock, with white axillary and pubic hair. Body hair in the areas of skin depigmentation was also white. Eyebrows were partially white, but there was no synophrys. Nagao et al. (1975), found the depigmented lesion of a case of piebaldism 
and presents mast cells found in the epidermis by electron microscopic study. In addition, different cases in India, reported by Agarwal \& Ojha (2012), were observed in two babies, with a similar distribution of depigmentation in their father, they alike in other piebaldism but did not present in their limbs.

Besides piebaldism, there are another congenital genetically inherited disorder; albinism and Waardenburg syndrome (WS). Albinism is characterized by the partial or complete absence of melanin production in the skin, hair, and eyes (Merrill et al., 2004; Kirkwood, 2009). Waardenburg syndrome (WS) is an autosomal dominant disorder characterized by piebald-like pigmentary anomalies of the skin and hair, pigmentary abnormalities of the iris (heterochromia irides), lateral displacement of the in ner canthi of the eyes (dystopia canthorum), and sensorineural deafness (Krishtul \& Galadari, 2003; Song et al., 2016; Vichare \& Bhargava, 2013). Different types of vitiligo may rarely be present at birth, but is usually acquired later in life, is unstable and is not genetically inherited, although it may run in some families. Based on characteristic of various melanin disorder, thus to person with the appearance, presence of white forelock in the frontal region, typical distribution of depigmented macules, their relative stability since the time of appearance and presence of a similar pattern of depigmented macules in other family members could be confirmed as piebaldism (Agarwal \& Ojha, 2012; Park et al., 2014; Bassi et al., 2015).

Oiso \& Kawada (2012), following by Saleem (2019), found the association of hearing loss and pigment abnormalities results from an abnormal proliferation, survival, migration, or differentiation of neural crest-derived melanocytes. Based on the interview to suspect, we found that there are suspect of To Balo had a disorder of their hearing. Even no strong evidence of association of hearing loss with these abnormalities, but it can be used as a reference for further observations. Oiso et al. (2013), state a review of the significant or complete loss of melanocytes in the ventral white patches and white hair is produced by inadequate migration of melanoblasts in the embryo. Therefore, a severe phenotype showing larger leukoderma is associated with severely damaged migration in the embryo. After identification of a missense mutation in the KIT gene on the chromosome 4q12 in a large family, 32 missense mutations, 17 deletions, four insertions, seven nucleotide splice-site mutations, two nonsense mutations, and one pericentric chromosomal inversion have been identified in the KIT gene or the chromosomal region of the KIT gene. These genetic studies indicate that the clinical features and phenotypic rigorousness of piebaldism associated with the site and the type of mutation in the KIT gene.

Recently, numbers of KIT mutation has been described in association with piebaldism, including Gly610Asp, Glu640Asp, Arg791Gly, Cys674Tyr; Tyr675Ser, Phe811Val, and Arg812Val. Dinani et al. (2019), reported an Iranian 40-year old male with hypopigmented skin lesions on his face and limbs who diagnosed as a case of piebaldism. For the investigation of novel possible mutations of KIT result in piebaldism, they amplified and sequenced this gene from the patient and one control individual. 
Genetic analysis identified a heterozygous SNP of the KIT gene, rs999020, which results in the substitution of $\mathrm{T}$ allele at position 54658137 to $\mathrm{C}$ allele in the patient. Furthermore, a homozygous rs1008658 SNP of this gene was also found at position 54733270 , the substitution of $\mathrm{T}$ allele to $\mathrm{C}$ allele, in the patient. Nomura et al. (1998), described a novel KIT gene missense mutation (Thr847Pro) in a Japanese family with piebaldism that supportive evidence that missense mutation within the tyrosine kinase domain produces a severe phenotype.

\section{Analyze of Pedigree in To Balo}

\section{a. Probands A1}

Figure 3 showed that the father of A1 has a history of white patches of skin (Balo) and then married a normal-skinned person. From this marriage, five children were born with white patches (Balo) with the sex of 3 boys and two girls. However, the four siblings of A1 have died, and A1 is left alone. A1 (56 yo) (FII.3) was born as a suspect of piebaldism (To Balo), has a history of piebaldism hereditary. He is then married to normal none To Balo community. Throughout his marriage, A1 did not have children (infertile). Seen from the father and five siblings, A1 has the exact pattern of white patches (Piebaldism).

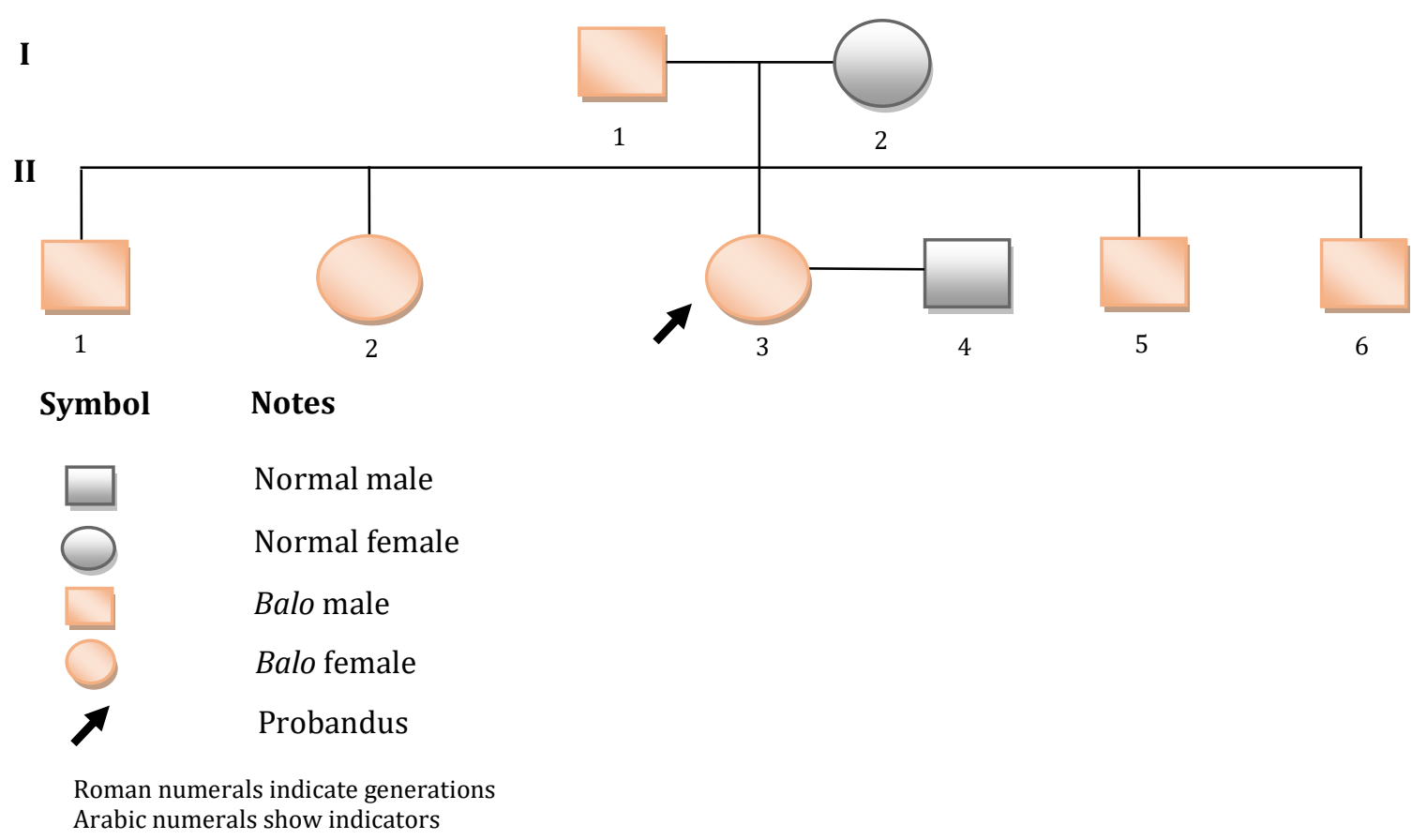

Figure 3. Pedigree of A1 


\section{b. Probands B2}

Figure 4 presented the father of B2 has a history of white patches of skin (Balo) and then married a normal-skinned person. From this marriage obtained, two children were born with white male patches (Balo). B2 (48 yo) was born suffering from vitiligo (Balo), has a history of vitiligo which was passed down by his father, then married with normal women. Throughout his marriage, B2 had five children, 3 of whom suffered from Balo, and two were normal, with the sex of 2 boys and three girls. Viewed from the father, B2 and his three children have the exact white patches (piebaldism trait). As for the complaints felt by B2, his views are sometimes rather vague.

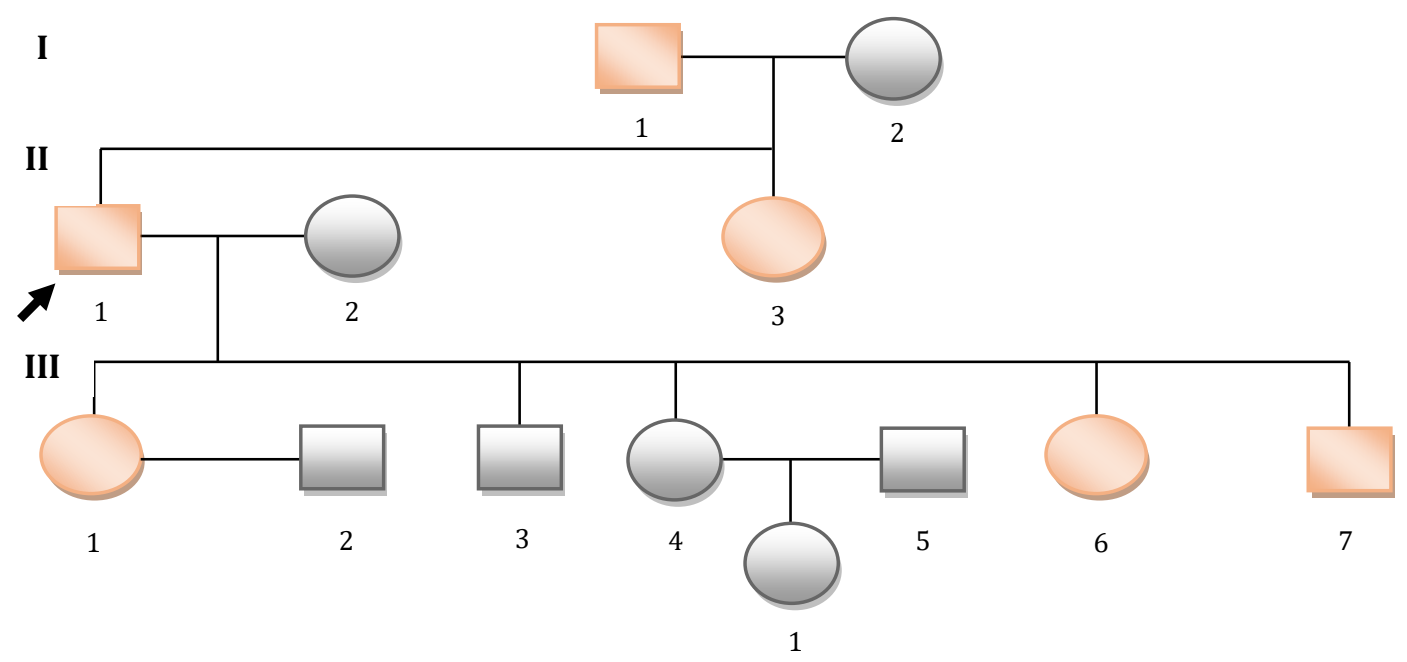

$$
\begin{array}{ll}
\text { Symbol } & \text { Notes } \\
& \begin{array}{l}
\text { Normal male } \\
\text { Normal female } \\
\end{array} \\
& \text { Balo male } \\
& \text { Palo female }
\end{array}
$$

Roman numerals indicate generations Arabic numerals show indicators

Figure 4. Pedigree of B2

Based on the literature, piebaldism is categorized as a dominant autosomal. From the pedigree of suspect shown above, then we analyzed based Mendelian inheritance and confirmed that suspect To Balo was piebaldism. This is based on analysis:

a. Normal kids only obtained if both parents are homozygote recessive, shown in pedigree B2, III4 X III5 (Figure 4). A marriage between men and women heterozygote was found to have children with piebaldism, this is expected if both 
parents do not have piebaldism genotype heterozygote (carrier) and children with piebaldism receive a pair of recessive alleles originating from both parents.

b. If piebaldism genotypes are homozygous dominant, the marriage between two piebaldism people homozygote and heterozygote will found all piebaldism (Table 1), unless if neither are heterozygote, marry with normal (homozygote recessive) then will result in kids with piebaldism and normal in the ratio 50\%: 50\% (Table 2).

$\begin{array}{cccc}\text { Parental (P1) : } & \begin{array}{c}\text { aa } \\ \text { (normal) }\end{array} & >\begin{array}{c}\text { AA } \\ \text { (piebaldism) }\end{array} \\ \text { F1 } & : & \text { Aa (carrier } / \text { piebaldism) }=100 \%\end{array}$

If F1 married with piebaldism, then:

$\begin{array}{ccccc}\text { Parental } & : & \text { Aa } & >< & \text { AA } \\ \text { F2 } & : & & 100 \% \text { piebaldism }\end{array}$

Table 1. Fertilization of heterozygote piebaldism and piebaldism

\begin{tabular}{ccc}
\hline o & $\mathbf{A}$ & $\mathbf{A}$ \\
\hline $\mathbf{A}$ & $\mathrm{AA}$ & $\mathrm{AA}$ \\
$\mathbf{a}$ & $\mathrm{Aa}$ & $\mathrm{Aa}$
\end{tabular}

Ratio genotype AA : Aa 50\% : 50\%; Phenotype 100\% piebaldism

Table 2. Fertilization of heterozygote piebaldism and normal

\begin{tabular}{ccc}
\hline $\mathbf{o}^{\mathbf{a}}$ & $\mathbf{a}$ & $\mathbf{a}$ \\
\hline $\mathbf{A}$ & Aa & Aa \\
\hline $\mathbf{a}$ & aa & aa
\end{tabular}

Ratio phenotype Aa : aa 50\%: 50\%; Genotype normal: piebaldism 50\%: 50\%

Above is the pattern of inheritance from parents to their child, confirmed that To Balo, genetically inheritance as autosomal dominant. It means a pattern of heritance in which an affected individual has one copy of a mutant gene and one normal gene on a pair of autosomal chromosomes. The individual with an autosomal dominant disease has a 1 in 2 (50 percent) chance of inheriting the mutant gene copy.

\section{Conclusion}

Based on phenotypic observations of the pattern of depigmentation and genetically inheritance, To Balo corresponded to piebaldism. The pattern of depigmentation in To Balo generally similar in all piebaldism, but the distribution in To Balo has different patches, besides white forelock, ventral trunk, limbs, lower 
extremities, but also dominant found in the dorsal trunk. Normal individuals can appear in third-generation when a woman or man carrier of piebaldism married with a normal individual. Thus, to prevent these traits rises in the next heredity, To Balo should marry beyond of community to get normal heredity. In a further study, we would identify the heterozygous SNP of the KIT gene in To Balo.

\section{Acknowledgment}

This study was supported by the Head of the government of Barru District, Province of South Sulawesi, Ir. H. Suardi Saleh, M.Si. We are grateful to the head of the sub-district, Abd. Rahman, SE, and to all individuals of To Balo community who participated in this study.

\section{References}

Agarwal, S., \& Ojha, A. (2012). Piebaldism: A brief report and review of the literature. Indian Dermatology Online Journal, 3(2), 144. https://doi.org/10.4103/22295178.96722 .

Arianayagam, S., \& Ryan, T. J. (2016). Disorders of pigmentation of the skin-hypotheses underlying interventions by multiple systems of medicine: is there a role for integrated medicine?. Current Science, 111(2), 325-336. https://doi.org/10.18520/cs/v111/i2/325-336

Bassi, A., Berti, S., \& Galeone, M. (2015). Piebaldism. QJM: An International Journal of Medicine, 108(11), 915-915. https://doi.org/10.1093/qjmed/hcv101

Dinani, S. T., Ghaedi, K., Safinejad, K., \& Nasr-Esfahani, M. H. (2019). Piebaldism: An Iranian case report carrying minor allele at rs999020 and rs1008658 SNPs of KIT gene. Gene Reports, 17, 1-21. https://doi.org/10.1016/j.genrep.2019.100544

Funkhouser, C. H., Kinsler, V. A., \& Frieden, I. J. (2019). Striking contiguous depigmentation across the lower limbs in piebaldism and its implications for understanding melanocytic migration and development. Pediatric dermatology, 36(4), 511-513. https://doi.org/10.1111/pde.13831

Hazan, C. (2005). Piebaldism. Dermatology online journal, 11(4), 18.

Janjua, S. A., Khachemoune, A., \& Guldbakke, K. K. (2007). Piebaldism: a case report and a concise review of the literature. Cutis, 80(5), 411-414.

Kirkwood, B. (2009). Albinism and its implications with vision. Insight, 34(2), 13-16.

Koley, S., Salodkar, A., Saoji, V., \& Choudhary, S. (2009). Piebaldism and Vitiligo in Two brothers. Iranian Journal of Dermatology, 12(3), 8-11. 
Krishtul, A., \& Galadari, I. (2003). Waardenburg syndrome: Case report. International journal of dermatology, 42(8), 651-652. https://doi.org/10.1046/j.13654362.2003.01949_3.x.

Merrill, K. S., Lavoie, J. D., King, R. A., \& Summers, C. G. (2004). Positive angle kappa in albinism. Journal of American Association for Pediatric Ophthalmology and Strabismus, 8(3), 237-239. https://doi.org/10.1016/j.jaapos.2004.01.002

Murakami, T., Fukai, K., Oiso, N., Hosomi, N., Kato, A., Garganta, C., Barnicoat, A., Poppelaars, F., Aquaron, R., Paller, A. S., Ishii, M. (2004). New KIT mutations in patients with piebaldism. Journal of dermatological science, 35(1), 29-33. https://doi.org/10.1016/j.jdermsci.2004.03.003

Nagao, S., Iijima, S., \& Shima, T. (1975). Mast cells in the epidermis of piebaldism. Archives for Dermatological Research, 251(3), 221-225. https://doi.org/10.1007/BF00561763

Neves, D. R., Regis Junior, J. R., Oliveira, P. J., Zac, R. I., \& Silveira Kde, S. (2010). Melanocyte transplant in piebaldism: case report. Anais Brasileiros de Dermatologia, 85(3), 384-388. https://doi.org/10.1590/s0365-05962010000300016

Nomura, K., Hatayama. I., Narita, T., Kaneko, T., Shiraishi. M. (1998). A novel KIT gene missense mutation in a Japanese family with piebaldism. The Journal of Investigative Dermatology. 111(2): 337-338. https://doi.org/10.1046/j.1523-1747.1998.00269.x

Oiso, N., Fukai, K., Kawada, A., \& Suzuki, T. (2013). Piebaldism. Journal of Dermatology, 40(5), 330-335. https://doi.org/10.1111/j.1346-8138.2012.01583.x

Oiso, N., \& Kawada, A. 2012. Skin anatomy and physiology research developments in melanocytes. Melanin: Biosynthesis, Functions and Health Effects. New York: Nova Science Publisher, Inc. pp. 167-190.

Park, H. S., Jang, S. J., Lee, Y. S., \& Chun, D. K. (2002). Four Generations of Piebaldism. Korean Journal of Dermatology, 40(10), 1273-1276.

Park, S. Y., Kim, H. J., \& Ahn, S. K. (2014). Piebaldism with neurofibromatosis type I: a familial case. Annals of dermatology, 26(2), 264-266. https://doi.org/10.5021/ad.2014.26.2.264

Richards, K. A., Fukai, K., Oiso, N., \& Paller, A. S. (2001). A novel KIT mutation results in piebaldism with progressive depigmentation. Journal of the American Academy of Dermatology, 44(2), 288-292.

Rochmawati, D. A. N. (2016). Hubungan perkawinan endogami dengan kelainan bawaan lahir. Antro Unair Dot Net, 5(2), 246-257.

Sabran, A. A., Agus, R., \& Hatta, M. (2018). Aspek genetika waran kulit kelompok komunitas to balo di Sulawesi Selatan. Bioma: Jurnal Biologi Makassar, 3(1), 48-54. http://doi.org/10.20956/bioma.v3i1.5561 
Saleem, M. D. (2019). Biology of human melanocyte development, Piebaldism, and Waardenburg syndrome. Pediatric dermatology, 36(1), 72-84. https://doi.org/10.1111/pde.13713

Song, J., Feng, Y., Acke, F. R., Coucke, P., Vleminckx, K., \& Dhooge, I. J. (2016). Hearing loss in Waardenburg syndrome: a systematic review. Clinical genetics, 89(4), 416-425. https://doi.org/10.1111/cge.12631

Spritz, R. A. (2007). The genetics of generalized vitiligo and associated autoimmune diseases. Pigment Cell Research, 20(4), 271-278. https://doi.org/10.1111/j.16000749.2007.00384.x.

Vichare, N., \& Bhargava, N. (2013). Waardenburg syndrome: A rare case with bilateral congenital cataract: An unusual entity. Medical journal, Armed Forces India, 69(2), 172. https://doi.org/10.1016\%2Fj.mjafi.2012.02.017

Winship, I., Young, K., Martell, R., Ramesar, R., Curtis, D., \& Beighton, P. (1991). Piebaldism: an autonomous autosomal dominant entity. Clinical Genetics, 39(5), 330-337. https://doi.org/10.1111/j.1399-0004.1991.tb03039.x

Yang, Y. J., Zhao, R., He, X. Y., Li, L. P., Wang, K. W., Zhao, L., Tu, M., Tang, J. S., Xie, Z. G., \& Zhu, Y. M. (2013). A novel splicing mutation of KIT results in piebaldism and auburn hair color in a Chinese family. BioMed research international, 2013: 1-6. https://doi.org/10.1155/2013/689756 